\title{
MARKET BARRIERS TO ENERGY EFFICIENCY
}

UC-350

\author{
Richard B. Howarth and Bo Andersson'
}

LBL -32541

June 1992

DE93 001587

\begin{abstract}
Discussions of energy policy in an environmentally constrained world often focus on the use of tax instruments to internalize the external effects of energy utilization or achieve specified reductions in energy use in the most cost-effective manner. A substantial literature suggests, however, that significant opportunities exist to reduce energy utilization by implementing technologies that are cost-effective under prevailing economic conditions but that are not fully implemented by existing market institutions. This paper examines the theory of the market for energy-using equipment, showing that problems of imperfect information and transaction costs may bias rational consumers to purchase devices that use more energy than those that would be selected by a well-informed social planner guided by the criterion of economic efficiency. Consumers must base their purchase decisions on observed prices and expectations of postpurchase equipment performance. If it is difficult or costly for individuals to form accurate and precise expectations, the level of energy efficiency achieved by competitive markets will vary from the socially efficient outcome. Such "market barriers" suggest a role for regulatory intervention to improve market performance at prevailing energy prices.
\end{abstract}

\footnotetext{
1 Energy and Environment Division, Lawrence Berkeley Laboratory, Berkeley, California, U.S.A.; and Stockholm School of Economics, Stockholm, Sweden, respectively. The authors acknowledge support from the Norwegian Research Council, the Swedish National Energy Administration, and the Stockholm School of Economics. Additional funding was provided by the Stockholm Environment Institute under U.S. Department of Energy Contract No. DE-AC03-76SF00098. Lars Bergman, Olav Bjerkholt, Kjell Ame Brekke, Eystein Gjelsvik, Jon Koomey, Jim McMahon, Richard Norgaard, Lee Schipper, Steinar Strom, and especially Alan Sanstad provided
} valuable comments and suggestions. 


\section{Introduction}

The efficacy of the market mechanism in achieving a socially desirable level of energy efficiency has generated considerable debate in policy circles and the academic literature. According to the simplest neoclassical models of competitive markets, perfectly informed, rational individuals consider the total costs of their decisions when purchasing energy-using equipment. If the value of the energy savings generated by improving the energy efficiency of a device exceeded the cost of the improvement, competitive producers could increase their profits by exploiting consumers' willingness to pay for the change. It follows under these assumptions that all efficiency measures that were cost-effective at prevailing prices would be realized by competitive markets. The problem of energy policy would thus be reduced to ensuring that energy prices reflected the full social costs of energy production and utilization (Sutherland, 1991).

The validity of this idealized model as a description of observed reality has been cast into doubt by microeconomic studies of the costs and benefits of energy-efficient technologies. Hausman (1979), for example, conducted a study of consumer purchases of air conditioners and found that consumers could achieve considerable present-value savings by switching from the models actually purchased to more energy-efficient alternatives. Observed consumer behavior would be consistent with life-cycle-cost minimization only at a discount rate of 25 percent per annum averaged across income groups. Implicit discount rates fell sharply with higher incomes; low-income groups behaved as though they used discount rates of up to 89 percent. In a similar vein, Ruderman et al. (1984), focusing on sales of residential appliances and heating and cooling equipment, estimated implicit discount rates ranging from 20 to 800 percent per annum - well above the returns available on other investments.

The factors behind the so-called "efficiency gap" - the differential between the level of 
energy-efficiency actually achieved and the level judged to be cost-effective at prevailing prices - have been explained mainly in terms of "market barriers" related to consumer decision-making (Carlsmith, et al. 1990). Consumers are said to lack full information regarding available energy-efficient technologies, use a discount rate that is "too high" in evaluating investments in energy efficiency, or simply lack the means to carefully evaluate the consequences of their decisions. In some cases, such as the rental housing market, the costs and benefits of energy efficiency improvements may accrue to different agents, splitting the incentive to invest in otherwise attractive technologies. Finally, transactions costs may swamp the often small net benefits achievable by individual consumers (Krause and Eto, 1988).

Issues relating to the supply of energy-using equipment may also induce barriers to the development and adoption of energy-efficient technologies. It is well known that private firms are unable to capture the full social benefits of research and development expenditures, especially when markets are fragmented or patent protection is easily circumvented through "copycat" inventions (Arrow, 1962; Kamien and Schwartz, 1982). Such eventualities suggest a potential role for government in supporting research and development (Fisher and Rothkopf, 1989). Indeed, the empirical literature suggests that existing government-sponsored projects to develop energy-efficient technologies have reaped rich rewards (Geller et al., 1989; Rosenfeld, 1991).

The existence of an efficiency gap suggests the possibility that energy use may be reduced relative to status quo levels at a net cost saving. A study by the U.S. National Academy of Sciences (1991), for example, concluded that energy-related emissions of carbon dioxide could be reduced by as much as 37 percent through the adoption of energy-efficient technologies that are cost-effective under current economic conditions.

As Grubb (1990) frames the issue, the achievement of an ideal level of energy efficiency 
involves a two-step process (Figure 1). First, energy prices should be set to reflect the full social costs of energy production ar 1 utilization, including external environmental costs. Proper pricing shifts the energy supply curve inward from the $S$ to $S$. Second, policies should be implemented to improve market performance given prevailing prices, shifting the demand curve from the laissez faire $D$ to the cost-effective $D^{\bullet}$ without reductions in energy services. Only when these measures are implemented in tandem is energy use reduced from the status quo $E$ to the socially efficient level $E^{*}$ without incurring offsetting social costs. ${ }^{2}$

Such arguments have had a significant impact on energy policy. In some jurisdictions, governments require utilities to exploit opportunities to reduce electricity demand as part of their long-term planning. Environmentalists are arguing for tougher automobile fuel economy standards on the grounds that such standards would provide not only energy but also economic savings. Appliance efficiency standards are now an accepted part of U.S. energy policy and are under consideration in other nations.

The economic underpinnings of the presumed efficiency gap, however, have not been firmly established. While a plausible case may be made that market barriers impede the adoption of certain energy-efficient technologies, little effort has focused on the analysis of these barriers using formal models rooted in economic theory. The argument that consumers use especially high discount rates in evaluating the present-value costs of energy-using technologies, for example, is theoretically objectionable. Why would a rational person pass up a 20 to 800 percent return when alternative investments yield only 5 to 10 percent? Either the facts are

\footnotetext{
2 This point was made in the mid 1970s by Schipper (1976, pp. 457-8), who argued that "energy conservation [is] the strategy of adjusting and optimizing energy-using systems and procedures so as to reduce energy requirements ... while holding constant or reducing total [system] costs... The largest stimulus to more efficient energy utilization will occur in response to direct economic incentives and governmental policies designed to aid those incentives."
} 
wrong, consumers are "irrational" in the sense that they do not evaluate energy-using technologies in a manner consistent with life-cycle cost criteria, or there is more to the story than meets the eye.

Before proceeding further, we wish to establish two caveats. First, there is some disagreement regarding the potential for cost-effective energy savings. In-depth engineering studies, for example, indicate that raising the fuel economy of new U.S. automobiles beyond 36 to 44 miles per gallon of gasoline by the year 2000 (as compared to the current level of 28 miles per gallon in government tests) would entail a tradeoff between higher costs and reductions in vehicle amenities such as size and safety (Difiglio et al., 1990; Ledbetter and Ross, 1990). Lovins and Lovins (1991, p. 447), on the other hand, maintain that prototype vehicles averaging some 71 to 92 miles per gallon present opportunities for cost-effective energy savings because such vehicles "should cost about the same to mass produce as ordinarily inefficient cars of comparable size." This claim is apparently based on anecdotal accounts of recent developments in vehicle technology; in the absence of careful data on manufacturing costs and vehicle performance, its general validity is difficult to ascertain.

Second, heterogeneity in the population of energy users may imply that technologies that are cost-effective on average are not cost-effective for some classes of consumers. For example, although electric heating systems are generally more costly than natural gas systems on a lifecycle-cost basis, electric space heaters may be cost-effective if used infrequently (as in vacation homes) since their capital requirements are low. Considerable attention to detail is required to identify the true costs of improved energy efficiency.

This paper presents a theoretical analysis of demand-side market imperfections that drive a wedge between the cost-effective level of energy efficiency and the level that is realized by the interaction of rational agents in the marketplace. We find that consumer perceptions regarding 
the performance of energy-using equipment have an important impact on the market potential of energy-efficient devices. Even when consumers correctly estimate and seek to minimize the total costs of equipment ownership, anomalies in the transmission of information between producers and consumers may result in an inadequate level of energy efficiency in unfettered competitive markets.

The range of market barriers to energy efficiency considered here is by no means exhaustive. The paper's purpose, however, is not to construct a comprehensive theory but rather to shed some light on an interesting and vexing set of issues. A principal finding is that frictionless models of competitive equilibrium are an incomplete and potentially misleading guide to energy policy. Good policy arguably involves more than simply "getting prices right." A potential role exists for governments to intercede when the vagaries of market institutions lead to lags in the development and adoption of energy-efficient technologies.

\section{Energy-Efficiency and Consumer Behavior}

While there is considerable variation in the range of energy-using technologies, raising the efficiency of a device generally increases the cost of manufacturing it but reduces the downstream costs borne by users. Equipment manufacturers thus have no direct incentive to produce efficient devices and will do so only to the extent demanded by consumers. We show below that competitive markets will fail to generate a socially efficient level of energy efficiency if their structural characteristics impede the frictionless transfer of information between market participants.

Of course the market will not converge on a socially efficient outcome unless energy prices reflect the full social costs of energy production and utilization. By "socially efficient", we mean that the costs and benefits of energy utilization - and investments in improved 
equipment performance - are equated at the margin. In our analysis we take prices as given and investigate the response of market participants to prevailing market conditions.

As we noted above, several alleged imperfections have been identified in the market for energy-using equipment. One of the first that comes to mind is consumers' possible lack of information concerning the characteristics of available technologies. One can safely assume that there is generally a positive cost associated with the dissemination of information. Equipment performance may be difficult to observe, and the costs of improving consumer information may exceed the expected benefits to private agents.

Principal-agent problems may also impede the adoption of energy-efficient technologies. In the typical example from the rental housing market, landlords would bear the costs of investments in improved energy efficiency while the resulting energy savings would accrue to the renters who pay the utility bills. ${ }^{3}$ If tenants were unable to perfectly observe building characteristics and transaction costs exceeded the benefits achievable through such investments, cost-effective energy savings would be passed-up even in a world of rational agents (Fisher and Rothkopf, 1989).

Consumers' uncertainty concerning the benefits of improved energy efficiency may also impede the uptake of energy-efficient technologies. As Sutherland (1991) notes, rational consumers may act as though they are using high implicit discount rates when making decisions under a high degree of uncertainty. Subjective uncertainty, however, may stem from the fact that precise estimates of energy prices and equipment performance are costly to obtain from the perspective of individual consumers. If the costs of gathering information were pooled across

\footnotetext{
${ }^{3}$ Landlords would be unwilling to pay for utilities since tenants would then have an incentive to overutilize energy services. Tenants would be unwilling to make investments in improved energy efficiency if they expected to move out before the benefits of the investments were substantially realized.
} 
individuals, substantial economies of scale could be achieved which could reduce the uncertainties associated with certain technologies.

Finally, a number of authors have noted that low-income households lack the access to credit required to finance investments in improved energy efficiency. Hausman's (1979) findings on this matter are highly suggestive: the appliance choices of low-income groups imply discount rates substantially in excess of the market rate of interest. The gap between the discount rates of low-income consumers and the returns availabie on capital markets suggests that significant social benefits may be garnered through programs providing loan guarantees or direct subsidies to improve the energy efficiency of low-income households.

\section{A One-Period Model}

To further explore some of the issues raised above we construct formal models that illustrate how competitive markets will fail to generate a socially efficient level of energy efficiency if their structural characteristics impede the effective transmission of information between market participants. Consider the following one-period model. There is a large number of identical individuals who divide their incomes between expenditures on an energyusing good ("a device") and other consumption items. Each device uses $e$ units of energy while the price of energy is $q$. The total cost of purchasing and using a device is thus $p+q e$.

Consumers are fully cognizant of their incomes and relative prices but are unable to directly observe the energy intensity of devices prior to sale. Based on advertising, discussions with sales representatives, and other information, however, consumers form a point expectation $e^{*}$ regarding equipment performance. Taking income and other prices as given, the demand for

devices is thus $x\left(p+q e^{\bullet}\right)$ with $x^{\prime}(\cdot)<0$. Given a choice between devices with differing 
energy intensities, consumers would choose the model that minimized the ex ante ownership cost $p+q e^{\bullet}$.

On the producer side, a large number of atomistic firms produce devices at the unit cost $c(e)$ such that $c^{\prime}(e)<0$ and $c^{\prime \prime}(e)>0$. Thus costs are convex and increase monotonically as energy efficiency improves or energy intensity falls. Suppose that we take income and energy prices as given and assume that the device market is in competitive equilibrium. What are the relevant equilibrium conditions pertaining to the price and energy intensity of devices? Clearly the price must be set equal to the incremental cost of manufacturing a device, or else new firms could enter the market at lower prices and earn positive profits. Thus $p=c(e)$, and profits are zero.

This, however, is only part of the solution since costs depend on energy intensity and $e$ is an endogenous variable. If consumers held perfect information regarding device energy intensity, we should expect an equilibrium to minimize the total cost of owning and using a device. Were this not the case, an opportunity would exist to produce a device better suited to consumer preferences, and producers would presumably rush to fill the void. In formal terms, an equilibrium with perfect information must minimize $c(e)+q e$ through the choice of $e$, a problem that yields the first-order condition

$$
c^{\prime}(e)=-q
$$

The interpretation of this condition is straightforward. At the margin, the cost of reducing the energy intensity of a device is set equal to the market value of the energy savings achievable through the change. Higher energy prices justify higher production costs, so energy intensity is a decreasing function of energy prices. Provided that the price of energy reflects its full social costs and that producers are using the best available technology, it is clear that this 
outcome is socially efficient since it equates the marginal costs and benefits of energy-intensity reductions. In a world of perfect information, consumers signal their preferences to producers through their market behavior, and producers respond by producing goods that satisfy those preferences as fully as possible.

Note, however, that the model does not impose the restriction that consumers hold perfect information regarding device energy intensity. Because they must commit to their purchase decisions based on potentially imperfect expectations regarding equipment performance (Russell and Thaler, 1985), consumers will favor devices that minimize the ex ante ownership cost $p+$ $q e^{*}$ whether or not the resulting outcome is optimal ex post. Suppose that the expected and actual levels of energy intensity are related by the differentiable function $e^{*}=f(e)$. This function captures the psychological processes that shape a consumer's beliefs based on the objective information at her/his disposal. Then the level of energy intensity that prevails in competitive equilibrium must solve the problem

$$
\underset{e}{\operatorname{Minimize}}\left\{p+q e^{*}=c(e)+q f(e)\right\}
$$

The first-urder condition for this problem takes the form

$$
c^{\prime}(e)=-q f^{\prime}(e)
$$

This expression differs significantly from the efficiency condition defined by equation (1), and it is clear that the two will coincide only where $f^{\prime}(e)=1$. In particular, the function $f(e)$ $=e+k$ will satisfy this criterion for any constant $k$, not just the obvious case where $k=0$ so that there is agreement between consumer expectations and the realized outcome. This is rather surprising, because it implies that a socially efficient level of energy intensity may arise even when consumers use biased estimators of device performance. Note, however, that $k \neq 0$ 
implies an inefficient level of device ownership since consumers will misjudge the total ownership costs on which their purchase decisions are based.

Conversely, conformance between consumers' equilibrium estimates of energy intensity and actual device performance is insufficient to ensure social efficiency. Suppose, for example, that subjective expectations are given by $f(e)=(e+1) / 2$, the unit cost function is $c(e)=1 / e$, and the price of energy is $q=2$. In equilibrium, these assumptions imply that consumer expectations and the prevailing level of energy intensity are identical at $e^{*}=e=(2 / \mathrm{q})^{1 / 2}=1$ as compared to the socially efficient level of $(1 / 2)^{1 / 2}$. Thus it is not the level of expectations per se that is relevant in determining market behavior. Instead, it is the relationship between expectations formation and the true characteristics of energy-using equipment, expressed here by $f(e)$.

Why would consumers base their expectations on anything but the observed characteristics of energy-using equipment? In reality, it may be costly or difficult to obtain precise and accurate estimates of equipment performance, justifying the use of simple rules of thumb when making purchase decisions. While a firm might advertise its product as achieving a particular performance standard, such information might be discounted by consumers who base their beliefs on factors such as their personal experience with equipment ownership.

Suppose, for example, that an individual consumer could observe a device's true energy intensity for a fixed cost $C$. Would it be rational for her to incur this cost? Assume for simplicity that the individual's device demand was fixed at $x$ and that a firm was willing to supply an efficient device at the price $p_{e f f}=c\left(e_{e f f}\right)$ such that $c^{\prime}\left(e_{e f f}\right)=-q$ such that ex post ownership costs were minimized. Then the net ex post benefit of obtaining perfect infornation would be 


$$
\left(p+q e-p_{\text {sff }}-q e_{\text {Qff }}\right) x-C .
$$

This expression could be either positive or negative depending on the parameters of the model. Where information costs were high, however, a rational consumer would have a clear incentive to base her behavior on imperfect expectations of equipment performance.

The analysis presented here indicates that the formation and content of consumer beliefs regarding the performance of energy-using equipment are fundamental to the market potential for energy-efficient devices. Because this subject has been investigated by behavioral scientists, we need not base our opinions on pure speculation or theoretical assertions. In summarizing the literature, Stern $(1986$, p. 205$)$ concludes that the information held by consumers regarding residential energy use "is not only incomplete, but systematically incorrect. Generally speaking, people tend to overestimate the amounts of energy used by - and that may be saved in technologies that are visible and that must be activated each time they are used." Such findings support the general theme of our argument and call attention to the role of expectations in understanding consumer behavior.

\section{Dynamics with Adaptive Expectations}

The relationship between consumer expectations and equipment performance is clarified by the following dynamic version of the model. Consumers purchase devices separately at sequential dates $t=1,2, \ldots$ As before, consumers know their incomes and prevailing prices but base their device purchase decisions on expectations regarding device energy intensity. Expectations are formed based on past ownership experience and observation of equipment currently on the market according to $e_{t}^{*}=\alpha e_{t-l}^{*}+(1-\alpha) e_{t}$ where $0<\alpha<1$.

Competitive firms produce devices using the constant unit cost function $c(e)$, and the 
price of energy is constant at $q_{t}=q$. In competitive equilibrium, device energy intensity must minimize ex ante ownership costs at each point in time, solving the problem

$$
\underset{q}{\operatorname{Minimize}}\left\{p_{t}+q_{t} e_{t}^{*}=c\left(e_{p}\right)+q\left[\alpha e_{t-1}^{*}+(1-\alpha) e_{l}\right]\right\} .
$$

This problem generates the first-order condition

$$
c^{\prime}\left(e_{2}\right)=-q(1-\alpha) .
$$

This equation implies that the level of energy intensity and hence the price of devices is constant over time, and since by assumption $\alpha>0$, energy intensity generally exceeds the socially efficient level where the costs and ex post benefits of improved energy efficiency are equated. As in the previous example, however, this outcome is consistent with the hypothesis that in equilibrium the expected and realized values of energy intensity are in agreement; such agreement will occur provided that the initial expectation $e_{0}^{\dot{0}}=e_{1}$. More generally, it is easily shcwn that $e_{1}$ converges quickly to $e_{1}$ regardless of the initial expectation unless $\alpha$ is very close to one. In other words, if observation of the actual characteristics of equipment currently on the market plays a significant but not fully decisive role in shaping consumers' expectations of equipment performance, the model implies reasonable agreement between expectations and reality but not necessarily a socially efficient level of energy intensity.

While the precise specification of the model is of course open to debate, the intuition that supports it is rather appealing. The fact that consumers must purchase equipment before they incur the resulting energy costs means that in practice expectations formation is critical to purchase decisions. It is reasonable to suppose that consumers are unable to perfectly observe equipment characteristics prior to sale and will thus attach some weight to their previous experience in owning and operating equipment amongst other factors. Because the expected and 
realized levels of energy intensity converge in the case under study, consumers have no incentive to change their mode of expectations formation. More generally, consumers will seek to improve the quality of the information at their disposal only where the expected benefits outweigh the costs. Thus expectational errors may persist where information is costly to obtain.

The point might be raised that equipment suppliers, who presumably know both the marginal cost of reducing energy intensity and the related marginal benefits, would have an incentive to offer contracts to provide device services at a cost below the level implied by the model. An energy service company, for example, could offer to provide both a device and the energy required to operate it for a fixed plice below prevailing ex ante ow: r rhip costs. Alternatively, manufacturers might guarantee the energy intensity of their devices. In the absence of transaction costs, such an arrangement would lead to an equilibrium with a socially efficient level of energy intensity. Indeed, private contractors provide such services in certain equipment markets.

Energy costs, however, are often small both in absolute terms and as a fraction of the total cost of owning and operating equipment. Thus the private gains to be won through the direct prnvision of energy services may swamp the associated marketing costs for some technologies. Similarly, the costs of contract monitoring and enforcement might well exceed uncertainties pertaining to energy costs, ruling out performance guarantees as an effective marketing tool. It is notoriously difficult to establish the field performance of energy-using equipment (Nadel and Keating, 1991). In practice, few would expect a building contractor to offer rebates to home buyers who claimed that their heating bills were higher than advertised unless the disparity was very large indeed. Finally, the problem of "moral hazard" might arise under either energy service contracts or performance guarantees. To the extent that the energy intensity of a device depends on user behavior, institutions that weaken user incentives to 
minimize direct energy costs might lead to reduced energy efficiency.

\section{The Role of Uncertainty}

The discussion so far assumes that consumers are identical in their beliefs and hold point expectations regarding equipment performance. In reality, however, the content of a consumer's beliefs depends on her cognitive processes and on the specific context in which she receives and evaluates information. It is likely, therefore, that beliefs will differ across individuals according to some frequency or probability distribution. A related issue is that consumers may recognize the fallibility of their expectations and take this uncertainty into account as they render decisions. Both of these factors have important implications for the uptake of energy-efficient technologies that are best addressed using stochastic models of market behavior.

Suppose there are two types of devices that provide uquivalent energy services. The unit cost and energy intensity of each class of equipment are fixed at $c_{i}$ and $e_{b}$, and the supply industry is competitive so that the device price $p_{i}$ is set equal to unit cost for $i=1,2$. The price of energy is $q$ so that the total cost of owning a device of type $i$ is $p_{i}+q e_{i}$.

There are $n$ consumers who each purchase exactly one device of either class 1 or 2 . Each consumer knows the values of $p_{1}, p_{2}$, and $q$ with certainty. Consumers do not, however, know the true values of $e_{1}$ and $e_{2}$ but form unbiased estimates drawn from the distributions

$$
e_{i}^{*}=e_{i}+u_{i}
$$

where $u_{i}$ is independently and normally distributed with mean 0 and variance $\sigma_{i}^{2}$. As in the models presented above, consumer expectations regarding equipment performance are based on imperfect observation of the products offered for sale.

Suppose that $e_{1}>e_{2}$ and $p_{1}+q e_{1}>p_{2}+q e_{2}$. These assumptions imply that 
technology 1 is clearly inferior because both its true energy intensity and ownership cost exceed those of technology 2 . Will technology 2 therefore drive technology 1 off the market? To answer this question requires a hypothesis conceming consumer behavior.

Consider first the case witere each consumer naively takes her estimates of $e_{1}$ and $e_{2}$ as the true values of these variables and purchases technology 1 if

$$
p_{2}+q e_{2}^{*}>p_{1}+q e_{1}^{*} \text {. }
$$

If the number of consumers is large and each forms her energy intensity estimates separately, the difference $e_{2}^{\dot{*}}-e_{1}^{\dot{j}}$ will take on large values with non-zero probability so that this condition will be satisfied for some portion of the population. This mole of behavior therefore implies a positive market share for a clearly inferior technology.

Now suppose that consumers recognize that their estimates of $e_{1}$ and $e_{2}$ are stochastic. In particular, we shall assume that they know the true values of $\sigma_{i}^{2}(i=1,2)$ and that they seek to maximize an expected utility function defined over their incomes net of device and energy expenditures. Assuming that consumers exhibit constant absolute risk aversion, they will purchase technology 1 if

$$
\mathrm{E}\left\{-\exp \left[-\lambda\left(I-p_{1}-q e_{1}\right)\right] \mid e_{1}^{*}\right\}>\mathrm{E}\left\{-\exp \left[-\lambda\left(I-p_{2}-q e_{2}\right)\right] \mid e_{2}^{*}\right\}
$$

where $\lambda$ is a positive parameter and $I$ is consumer income. Since $E[\exp (\lambda x)]=\exp \left(\mu+\lambda^{2} \sigma^{2} / 2\right)$ if $x$ is normally distributed with mean $\mu$ and variance $\sigma^{2}$, this condition may be written in the form

$$
-\exp \left\{-\lambda\left(I-p_{1}-q e_{1}^{*}-\frac{\lambda q^{2} \sigma_{1}^{2}}{2}\right)\right\}>-\exp \left\{-\lambda\left(I-p_{2}-q e_{2}^{*}-\frac{\lambda q^{2} \sigma_{2}^{2}}{2}\right)\right\} .
$$

Algebraic manipulation then shows that consumers will favor technology 1 if 


$$
p_{2}+q e_{2}^{*}+\frac{\lambda q^{2} \sigma_{2}^{2}}{2}>p_{1}+q e_{1}^{*}+\frac{\lambda q^{2} \sigma_{1}^{2}}{2}
$$

This relation is closely related to the naive decision rule given by eq. (8); the two coincide when $\sigma_{1}^{2}=\sigma_{2}^{2}$. As above, some consumers will purchase each technology, with individual decisions depending on the particular signals received. In general, the uncertainty consumers attach to their expectations alters their perceptions of the relative attractiveness of the two technologies. This is clearly seen in the case where $\sigma_{1}^{2}=0$ so that consumer uncertainty is limited to the more efficient technology. With this assumption, consumers will purchase technology 2 only if its expected cost savings relative to technology 1 exceed a threshold that increases with their degree of uncertainty.

Why is this an interesting case? Generally speaking, the most energy-efficient technologies are new to the market, and it is reasonable to suppose that consumers will lack familiarity with such products and thus attach a high degree of uncertainty to their performance. In a dynamic world, consumer uncertainty would presumably narrow with time and experience. In the meantime, however, rational consumer behavior permits the sustained use of outdated technolcgies.

As in the case of the deterministic one-period model discussed above, we may consider the ex post value of perfect information for the model in question. Suppose that consumers may reduce the variance of their energy intensity estimators $\sigma_{i}^{2}(i=1,2)$ to zero for a fixed cost $C$. Then the net ex post value of the information cannot exceed

$$
p_{1}+q e_{1}-p_{2}-q e_{2}-C .
$$

If the difference in user costs between the two technologies were small relative to the cost of obtaining perfect information, a rational consumer would choose to make her purchase decisions 
under uncertainty rather than incur costs yielding ambiguous net benefits.

\section{Policy Implications}

The models outlined above suggest several possible policy options and strategies. An obvious suggestion is that the government or some other independent agency should monitor and certify the performance of energy-using equipment. Indeed, this approach has been put into practice in the U.S., where labels are required on appliances and automobiles that indicate their energy intensity. While the approach is most practical for mass produced items, it is sometimes used in the housing market, where buildings that meet specific criteria may be certified as being energy efficient (Wilson et al., 1989).

On theoretical grounds, one would expect such labels to improve the information held by consumers to at least some extent. Empirical work has found, however, that performance labeling has ambiguous impacts on consumer decisions (McNeill and Wilkie, 1979; Robinson, 1991). Such a finding need not be inconsistent with the behavioral models set forth above. The cognitive processes by which consumers assess and internalize information are clearly relevant, and it may be costly or difficult to convey information to consumers in a manner that leads them to make "correct" decisions. As Sanstad et al. (in preparation) frame the issue, "it is not hard to reach a reductio ad absurdum in which the government undertakes the education in basic engineering economics of consumers upon their arrival at the department store appliance section."

A second approach would be the implementation of taxes or subsidies that adjusted the signals received by market participants. In our static model of the device market under point expectations, for example, an efficient allocation of resources would result if the government taxed device manufacturers at the unit rate $q[e-f(e)]$ where $f(e)$ is, as above, a representative 
consumer's expectation of device energy intensity. The equilibrium price of devices would then be

$$
p=c(e)+q[e-f(e)]
$$

and consumers' ex ante expectations concerning the costs of device ownership and ex post social costs would equilibrate at

$$
p+f(e)=c(e)+q[e-f(e)]+q f(e)=c(e)+q e .
$$

An equilibrium would minimize ex ante ownership costs, implying the first-order condition

$$
c^{\prime}(e)+q\left[1-f^{\prime}(e)\right]+q f^{\prime}(e)=0
$$

so that $c^{\prime}(e)=-q$. Thus the social costs and benefits of reducing energy intensity would be brought into agreement at the margin.

The informational requirements that must be met to identify an efficient tax regime, however, are particularly onerous. The government must know not only the level of consumer expectations but also the specific way in which they are formed, and this information must be effectively conveyed to manufacturers through the structure of the tax. In practice, such information may be very difficult to obtain, reducing the efficacy of tax instruments.

Such limitations suggest a potential role for the direct regulation of equipment performance. Energy efficiency standards are a key element of energy policy in the U.S., where the Corporate Average Fuel Economy standards led to demonstrable improvements in the fuel economy of automobiles in the 1970s and early 1980s (Greene, 1990). State and local governments set requirements concerning the thermal performance of building elements, although such requirements are often minimum acceptable standards that are surpassed in practice by private contractors. 
If performance standards are to pass the test of economic efficiency, they must be set to equate the marginal costs and benefits of reducing the level of energy intensity. A good example of this approach is embodied in the U.S. appliance efficiency standards, which are based explicitly on life-cycle-cost criteria. McMahon et al. (1990; see also U.S. Dept. of Energy, 1990) estimate that these standards will save 24 EJ of primary energy between 1990 and 2015. While the standards will increase equipment costs by $\$ 32$ billion in present-value terms, the associated energy savings are valued at $\$ 78$ billion. On balance, then, the standards are expected to yield net savings of $\$ 46$ billion.

Of course, the conformance of energy intensity to a socially efficient level does not mean that consumers correctly anticipate the ex post cost of equipment ownership, and this suggests that the demand for devices may fail to converge to an efficient level through the implementation of performance standards alone. In the models we have considered, this problem could be overcome through the taxation or subsidization of devices to span the gap between expected and realized ownership costs. Here it is the content rather th:n the functional determination of expectations that is relevant.

The variability of energy prices between regions raises interesting questions with respect to equipment performance standards. Should standards be uniform across regions, or should they be fine-tuned to reflect local conditions? Tollison and Ekelund (1987) examined this question for natural gas furnaces in the U.S., finding that increasing returns to scale in manufacturing favored the implementation of uniform standards. While uniform standards would imply a level of energy efficiency that was "too high" in low-price regions, reduced manufacturing costs would result in net cost savings for most consumers.

In terms of economic theory, government interventions are an appropriate means of reducing energy intensity in markets where informational anomalies inhibit the uptake of cost- 
effective energy-efficient technologies. Whether such interventions yield net reductions in energy use, however, depends on the characteristics of the demand for energy services. Generally speaking, policy interventions will reduce not only energy intensity but also the cost of using energy services. Thus policies designed to improve energy efficiency may increase the level of energy-using activities - the so-called "take-back" or "rebound" effect (Greene, 1992).

In the context of the dynamic model, suppose that $x=x(p+q e)$ with $x^{\prime}(\cdot)<0$ is the demand for devices when expected and realized energy intensity are stationary at the level $e$.

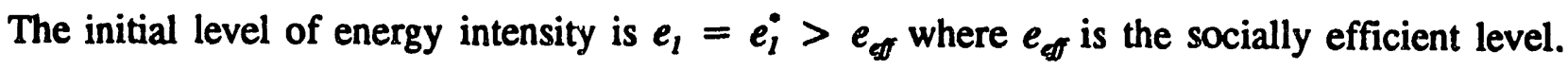
Now assume that the government introduces performance standards that reduce energy intensity to the efficient level and that expectations converge to $e_{\& f}$ over the long run. What is the resulting impact on energy use? We know that the price of devices is set equal to unit cost so that the stationary level of energy use is

$$
U(e)=e \cdot x(p+q e)=e \cdot x[c(e)+q e]
$$

A marginal decrease in $e$ will reduce long-run energy use if the derivative of this function obeys the restriction

$$
U^{\prime}(e)=x+e\left[c^{\prime}(e)+q\right] x^{\prime}(\cdot)>0 .
$$

Algebraic manipulation yields the equivalent condition

$$
\frac{e\left[q+c^{\prime}(e)\right]}{P}<-\frac{d P / P}{d x / x}
$$

where $P=p+q e$ is the total cost of device ownership. Reduced energy intensity thus implies reduced long-term energy use provided that the product of the energy intensity/ownership cost ratio times the wedge between the price of energy and the marginal cost of reducing energy 
intensity is less than the negative inverse of the total cost elasticity of equipment demand (the right-hand side of (18)). Note that this relation will hold unless the negative inverse elasticity exceeds the share of energy as a fraction of total ownership costs. As the energy cost share grows small the magnitude of the elasticity must become larger and larger for the relation to be violated. With an energy cost share of 10 percent, for example, the elasticity must be -10 or less if energy use is to grow with a reduction in energy intensity.

In reality, energy costs are usually a small fraction of the total cost of owning and operating energy-using equipment. Even in nations where gasoline is heavily taxed, for example, fuel expenditures generally account for less than 20 percent of the cost of owning and using an automobile. In most cases, there is little evidence that equipment demand is unusually elastic with respect to ownership costs. Hence we should generally expect energy use to fall with policy-driven reductions in energy intensity, although the decline in energy use may be less substantial than the reduction in energy intensity.

This expectation is generally confirmed by empirical studies of the impacts of reduced energy intensities. Dubin et al. (1986), for example, compared engineering calculations of the energy savings achievable through improvements in residential heating and cooling systems against actual performance. The engineering calculations overestimated savings by 1 to 13 percent for cooling systems and 8 to 12 percent for heating systems. Similarly, Greene (1992) found that increased vehicle utilization reduced the energy savings associated with improvements in the fuel economy of light-duty vehicles in the U.S. between 1966 and 1989 by only 5 to 15 percent.

\section{Conclusion}

This paper has shown how the structural characteristics of markets for energy-using 
equipment may impede the adoption of cost-effective energy-efficient technologies even whisimarkets are competitive and all market participants are rational. By rationality we mean that agents do the best they can given constraints on the resources and information at their disposal, including limits on their cognitive capabilities. A central theme is that the costs incurred by individuals in forming expectations of equipment performance lead them to render decisions under incomplete or imprecise information, biasing the market against investments in energy efficiency that would be made under perfect information.

While our arguments are theoretical and can be corroborated only through careful empirical research, we believe that they provide a degree of support to Grubb's (1990) view of proper energy policy in a world of demand-side market barriers to energy efficiency (Figure 1). In such a world, proper pricing and government programs designed to reduce market barriers to cost-effective energy efficient technologies are complementary policy instruments. Only when the two are implemented together is a socially efficient resource allocation achieved.

Economists commonly argue that decentralized private decision-making is preferable to collective action because it empowers individuals to make choices that foster their personal wellbeing. While the rationale for this perspective is compelling in many respects, we believe that enthusiasm for the market should be attenuated by a realistic understanding of the shortcomings and limitations of the market mechanism.

An individual acting alone is unlikely to hire an engineer to evaluate the costs and benefits of design improvements intended to reduce the energy intensity of a new refrigerator or heating system. Minimum performance standards based on cost-effectiveness criteria, on the other hand, might impose program costs that are small in comparison with the associated benefits. Poorly designed regulations would deny consumers access to desired attributes of energy-using technologies. Well designed standards, in contrast, would limit consumers' choices 
only in the trivial sense of eliminating options that no one would willingly exercise given perfect information and unlimited cognitive capacity.

\section{References}

Arrow, K. 1962. Economic Welfare and the Allocation of Resources for Inventions. In The Rate and Direction of Inventive Activity (R. Nelson, ed.). Princeton, New Jersey: Princeton University Press.

Carlsmith, R., W. Chandler, J. McMahon, and D. Santino. 1990. Energy Efficiency: How Far Can We Go? Oak Ridge National Laboratory ORNL/TM-11441.

Difiglio, C., K.G. Duleep, and D.L. Greene. 1990. Cost Effectiveness of Future Fuel Economy Improvements. Energy Journal 11(1): 65-86.

Dubin, J., A. Miedema, and R. Chandran. 1986. Price Effects of Energy-Efficient Technologies: A Study of Residential Demand for Heating and Cooling. Research Triangle Institute.

Fisher, A. and M. Rothkopf. 1989. Market Failure and Energy Policy. Energy Policy 17(4): 397-406.

Geller, H., J. Harris, M. Ledbetter, M. Levine, E. Mills, R. Morris, and A. Rosenfeld. 1989. The Importance of Government-Supported Research and Development in Advancing Energy Efficiency in the United States Building Sector. In Electricity - Efficient EndUse and New Generation Technologies, and Their Planning Implications (T. Johansson, B. Bodlund, and R. Williams, eds.). Lund: Lund University Press.

Greene, D.L. 1990. CAFE or Price? An Analysis of the Effects of Federal Fuel Economy Regulations and Gasoline Price on New Car MPG, 1978-1989. Energy Journal 11(3): $37-57$. 
Greene, D.I. 1992. Vehicle Use and Fuel Economy: How Big is the "Rebound" Effect? Energy Journal 13(1): 117-143.

Grubb, M. 1990. Energy Policies and the Greenhouse Effect. Volume One: Policy Appraisal. Dartmouth: Royal Institute of International Affairs.

Hausman, J.A. 1979. Individual Discount Rates and the Purchase and Utilization of EnergyUsing Durables. Bell Journal of Economics 10: 33-54.

Kamien, M.I. and N.L. Schwartz. 1982. Market Structure and Innovation. Cambridge: Cambridge University Press.

Krause, F. and J. Eto. 1988. Least-Cost Utility Planning. A Handbook for Public Utility Commissioners. Volume 2. The Demand Side: Conceptual and Methodological Issues. Lawrence Berkeley Laboratory.

Ledbetter, M. and M. Ross. 1990. A Supply Curve of Conserved Energy for Automobiles. Paper presented to the Intersociety Energy Conversion Engineering Conference, New York, New York.

Lovins, A.B. and L.H. Lovins. 1991. Least-Cost Climatic Stabilization. Annual Review of Energy and the Environment 16: 433-531.

McMahon, J.E., D. Berman, P. Chan, T. Chan, J. Koomey, M.D. Levine, and S. Stoft. 1990. Impacts of U.S. Appliance Energy Perforniance Standards on Consumers, Manufacturers, Electric Utilities, and the Environment. Proceedings of the ACEEE Summer Study on Energy Efficiency in Buildings 7: 107-116.

McNeill, D.L. and W.L. Wilkie. 1979. Public Policy and Consumer Information: Impact of the New Energy Labels. Journal of Consumer Research 6: 1-11.

Nadel, S.M. and K.M. Keating. 1991. Engineering Estimates vs. Impact Evaluation Results: How Do They Differ and Why? Paper presented to the Conference on Energy Program 
Evaluation: Uses, Methods, and Results.

Robinson, J.B. 1991. The Proof of the Pudding - Making Energy Efficiency Work. Energy Policy 7: 631-645.

Rosenfeld, A. 1991. The Role of Federal Research and Development in Advancing Energy Efficiency. Congressional testimony on the Department of Energy Conservation Budget Request. Lawrence Berkeley Laboratory.

Ruderman, H., M.D. Levine, and J.E. McMahon. 1987. The Behavior of the Market for Energy Efficiency in Residential Appliances including Heating and Cooling Equipment. Energy Journal 8(1): 101-124.

Russell, T. and R. Thaler. 1985. The Relevance of Quasi Rationality in Competitive Markets. American Economic Review 75: 1071-1082.

Sanstad, A.H., J.G. Koomey, and M.D. Levine. In preparation. On the Economic Analysis of Problems in Energy Efficiency: Market Barriers, Mariket Failures, and Policy Implications. Lawrence Berkeley Laboratory.

Schipper, L. 1976. Raising the Productivity of Energy Utilization. Annual Review of Energy 1: 455-517.

Stern, P.C. 1986. Blind Spots in Policy Analysis: What Economics Doesn't Say about Energy Use. Journal of Policy Analysis and Management 5: 200-227.

Sutherland, R.J. 1991. Market Barriers to Energy-Efficiency Investments. Energy Journal 12: $15-34$.

Tollison, R.D. and R.B. Ekelund, Jr. 1987. The Economic Efficiency of Federal Versus State Energy Conservation Standards for Appliances. Unpublished manuscript.

U.S. Department of Energy. 1990. Technical Support Document: Energy Conservation Standards for Consumer Products - Dishwashers, Clothes Washers, and Clothes Dryers. 
DOE/CE-0299p.

U.S. National Academy of Sciences. 1991. Policy Implications of Greenhouse Warming Report of the Mitigation Panel. Washington: National Academy Press.

Wilson, D., L. Schipper, S. Tyler, and S. Bartlett. 1989. Policies and Programs for Promoting Energy Conservation in the Residential Sector: Lessons from Five OECD Countries. Lawrence Berkeley Laboratory LBL-27289. 


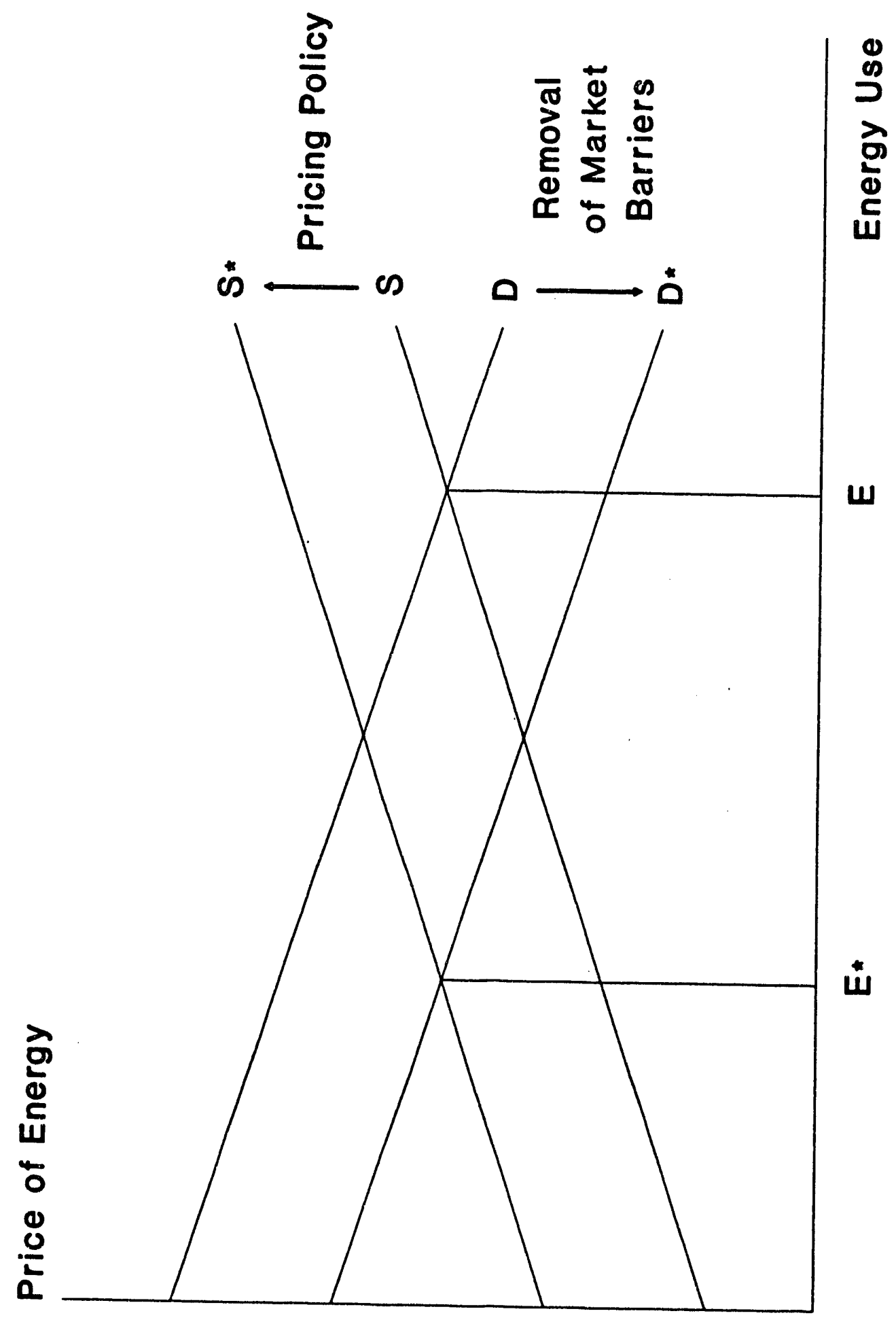

$\frac{5}{5}$ 

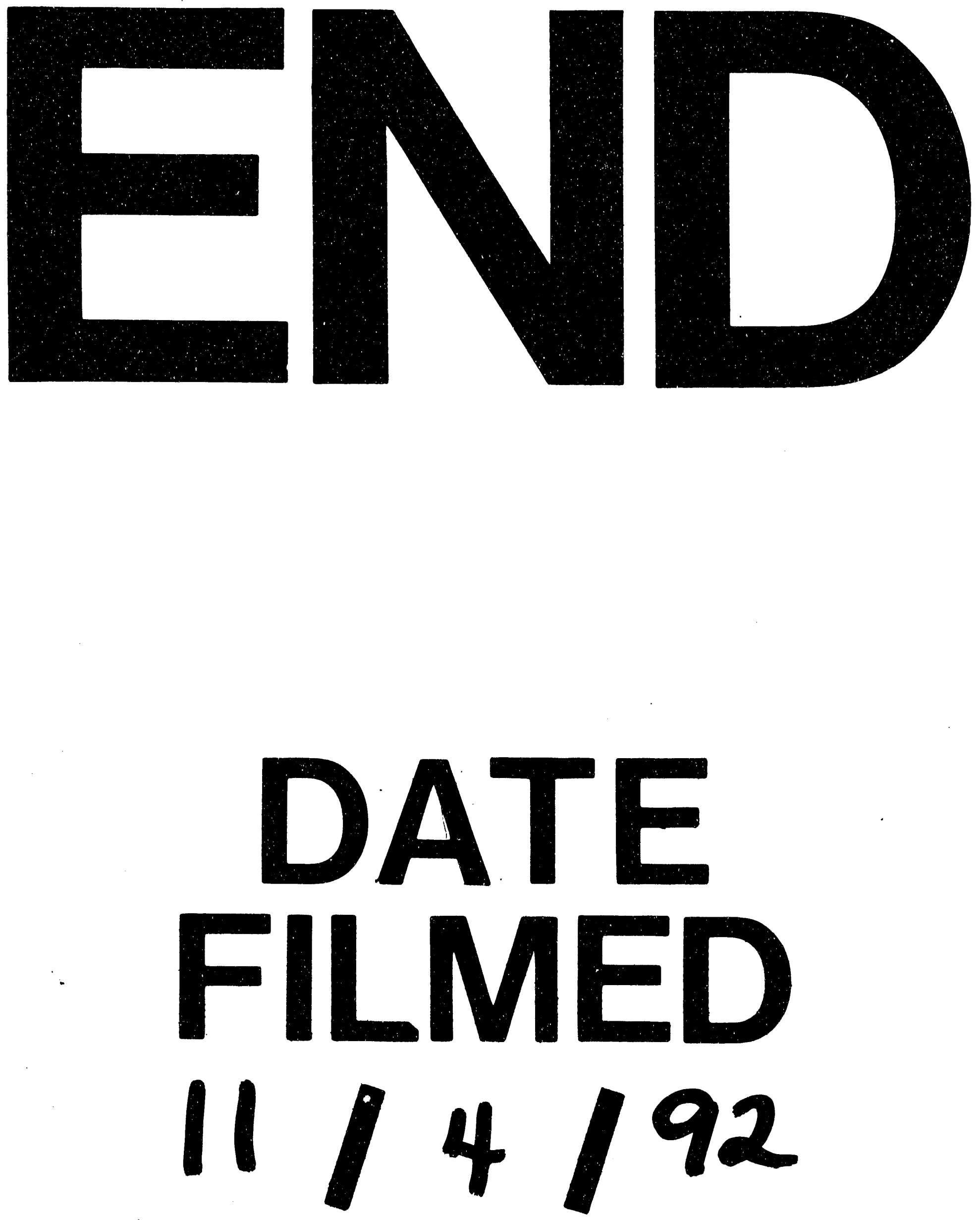

1 
